\title{
Classified Marketplace
}

\section{EMPLOYMENT OPPORTUNITIES}

\section{NURSE EPIDEMIOLOGIST}

Emanuel Hospital \& Health Center, a 350-bed Level I trauma center, has immediate full-time opening. Requires Oregon $\mathrm{RN}$ license and 3-5 years nursing experience in a hospital environment: experience as Nurse Epidemiologist preferred. BSN and CIC preferred. Interested applicants may call Gwen Sinclair at (503)280-4031 or send resume to Emanuel Hospital \& Health Center, Human Resources Department, 2801 N. Gantenbein Avenue, Portland, OR 97227, or fax her at (503)280-3757. A Legacy Health System member. Equal Opportunity Employer.

\section{SERVICES}

A FAX MACHINE IS AVAILABLE FOR YOUR CONVENIENCE. FAX YOUR CLASSIFIED AD TODAY for placement in the next available issue of INFECTION CONTROL AND HOSPITAL EPIDEMIOLOGY Classified Marketplace (609)853-5991.

\section{Classified Marketplace}

\section{re • sponse $\backslash r i-` s p a ̈ n(t) s \backslash$}

That's what you want from a classified ad. And Classified Marketplace lets you reach the audience you want-cost effectively-to get you the response you need.

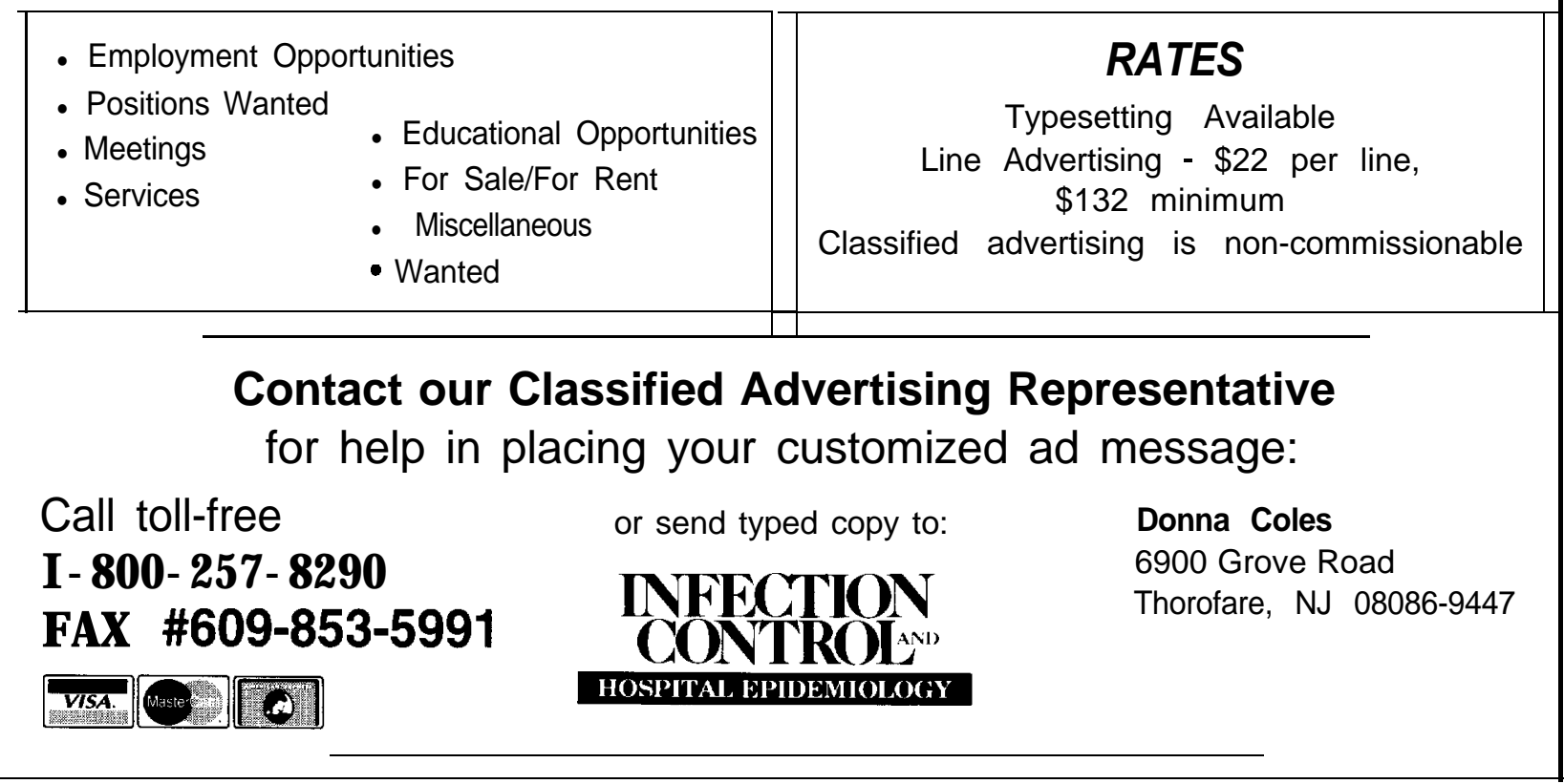



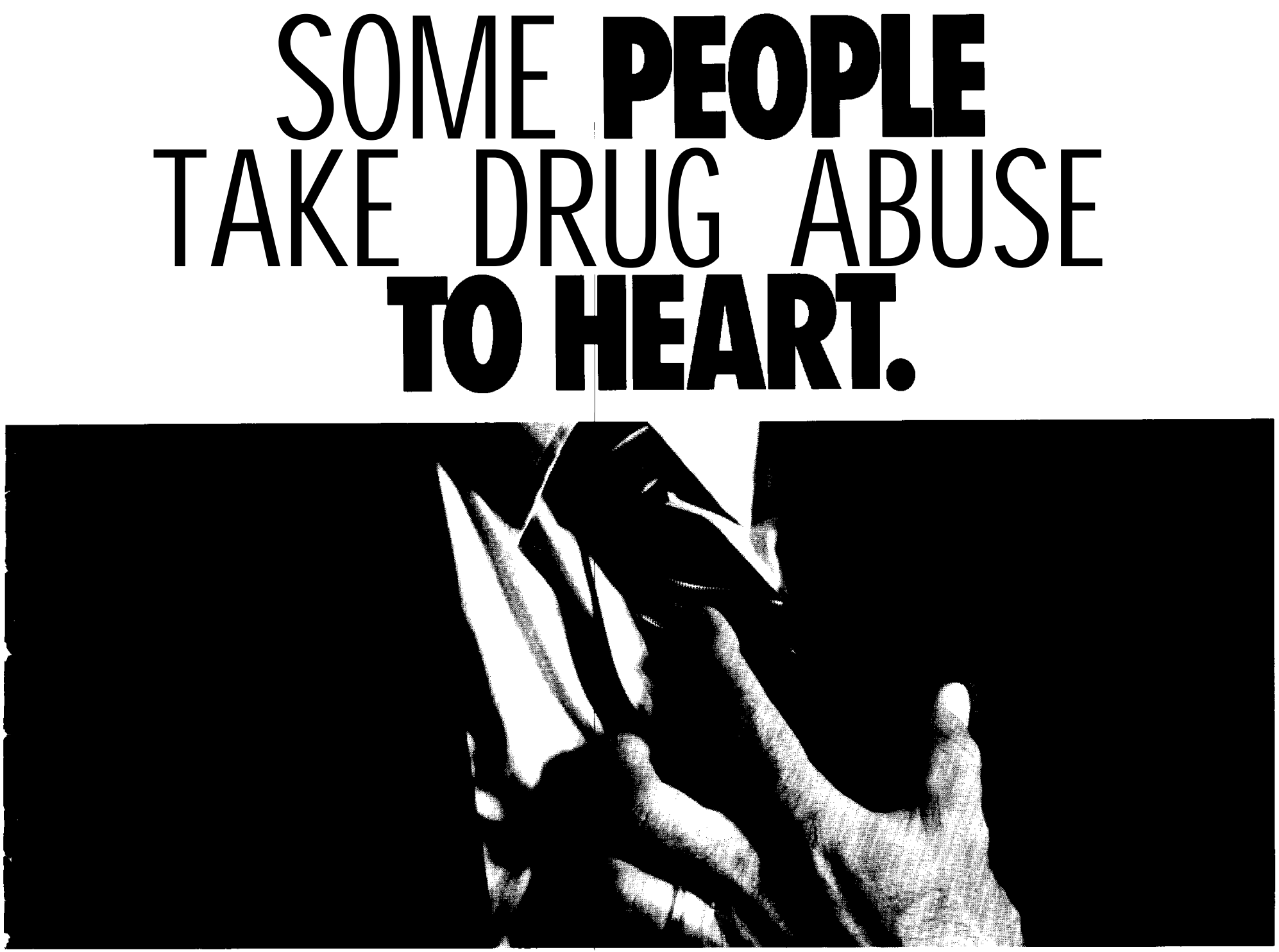

Most cocaine users are so dedicated! to the drug that what it does to their hearts never enters their minds. They don't realize that every time they use cocaine, they put themselves at risk for such potentially fatal cardiovascular complications as hypertensive crisis.. myocarditis.. . myocardial infarction ...ventricular tachycardia.. .ventricular fibrillation.. .even cardiac arrest.

Chances are, at least some of these people are your patients. And many of them may feel more comfort-

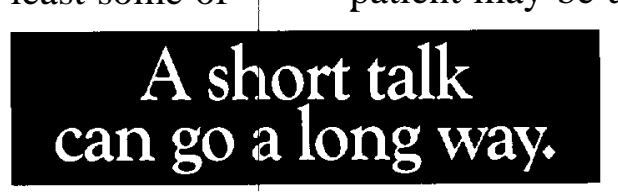

able telling a nurse what they can't-or won't-tell a doctor. That's why your role becomes critical in helping suspected drug abusers understand what illegal drug use does to their bodies. As key members of the health care team, nurses can make a difference in helping to curb drug abuse, and in preventing some of its deadliest consequences. The next time you suspect a patient may be using cocaine-or any illegal substancehave a heart-to-heart talk about the damage these drugs can do.

\section{Partnership for a Drug-Free America}




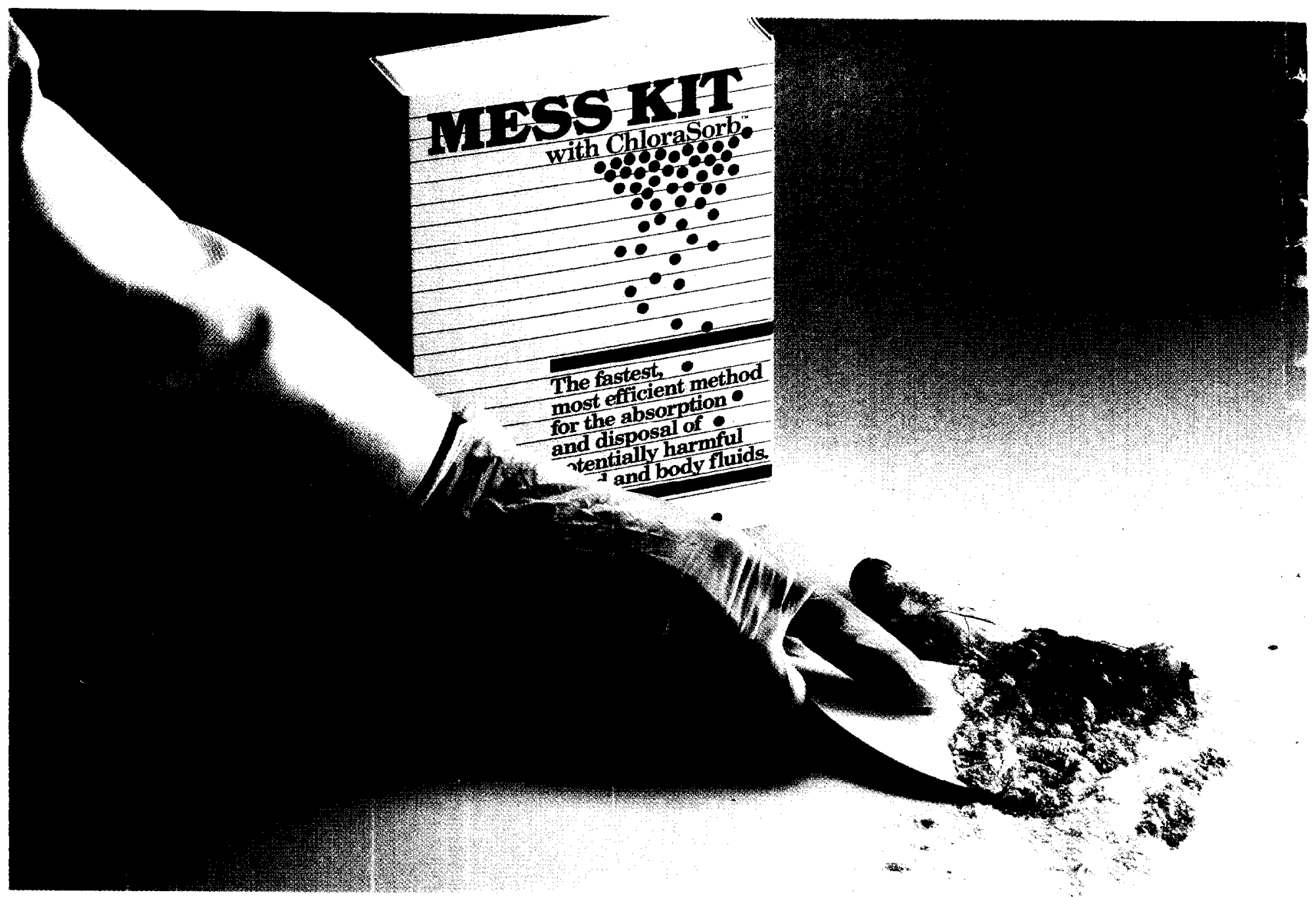

\section{The best solution for meeting QSHA requirements could also save lives.}

Cleaning and disposing of spilled body fluids has always been risky. Today, health care personnel are more concerned than ever. And rightfully so. How to handle blood or other potentially infectious materials has become a real problem. OSHA Regulation 29 CFR Part 1910.1030 states that you must assume these potentially infectious spills are contaminated and has set strict guidelines for dealing with them. That's why Huntington Laboratories offers the Mess Kit. The fastest, most efficient method for absorption and disposal of potentially harmful blood and body fluids.

Everything you need. Everything disposable. The Mess Kit is completely self-contained with easy to follow instructions. Just open the Mess Kit Package and you'll find everything you need.

- Seamless disposable gloves

- Self-sealing pouch of ChloraSorb stabilized chlorine compound

- Pick-up spatula

- Contaminated materials bag and tie

- Ready-to-use hospital grade germicidal detergent

- Wiping cloth

- Individual portion of antiseptic hand rinse

As you follow the step-by-step cleaning procedure you conveniently dispose of all the potentially harmful spill and everything that may have come in contact. You leave the area cleaned, disinfected and deodorized.

\section{Stabilized chlorine.}

National and state health authorities have consistently recommended the application of an active chlorine the amount available through the commonly recommended dilution of household bleach. And since ChloraSorb is a powdered stabilized compound, shelf life is no concern.

\section{All this protection in one little box.}

You'll never have to waste time tracking down the right equipment and supplies again. Everything will be at your fingertips, No more mixing a bleach solution. No more spreading your spill by adding more liquids. The Mess Kit was designed to

go everywhere. It stores easily in a small drawer or on a cart. The entire Mess Kit is smaller than a box of patient size facial tissue. It can be everywhere you need it. Everytime you need it.

For a demonstration of the Mess Kit and important information for in-service training, just contact your Huntington sales representative or call:

$$
\text { |-800-537-5724 }
$$

In Canada, call I-800-465-5227

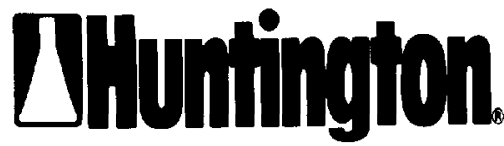

The Solutions Company 